\title{
The Challenges of Diplomacy in a Changing International Order
}

\author{
José Augusto Duarte
}

In 2020, when celebrating the International Day of Multilateralism and Diplomacy for Peace, United Nations Secretary General António Guterres said that "it is not enough to proclaim the virtues of multilateralism; we must continue to show its added value".

In a globalized and interconnected world, these words are a testimony to our common responsibility. More than words, we need action. And, that action needs to be geared towards protecting an international order that has allowed so many to be lifted out of poverty, that has established dialogue and cooperation as preferential means to handle and ideally solve disputes, and that has created the tools, institutions and rules to deal with such pressing global challenges as climate change.

Diplomacy, through words, and above all deeds, plays an essential part in protecting and developing that acquis and, most importantly, in taking forward concrete initiatives that aim at tackling common challenges that require joint and global action. To do so, it must balance reality and perception, be firm on universal values and principles, and uphold the rules and norms that shape the international system.

\section{The Importance of Reality and Perception}

As foreign policy is not conducted in a vacuum, it must not ignore the importance of context. A well-intentioned action may be perceived by others as something different. There lies one of the main tasks of a diplomat: understanding first and then explaining, thereby reducing the gap between reality and perception; a difficult task by any standard. One that was certainly made more challenging by the evolving nature of the international system.

J. A. Duarte $(\varangle)$

Embassy of the Portuguese Republic to the People's Republic of China, Beijing, China 
Fifty states signed the United Nations Charter in 1945. The organization now has 193 Member States. This extraordinary evolution has only increased the importance of dialogue, mutual understanding and cooperation.

When analysing today's world, one must not forget that while globalization has done much to reduce distances and increase connectivity, differences, sometimes substantial, still remain. Not only in political culture, but also in economic models and social norms. The temptation that may exist to use one single lens to analyse different realities is, therefore, short-sighted. To be aware of this complexity can be both alluring, as it challenges us to learn more about the other, and daunting.

One of the main challenges we face in today's world is, therefore, to know the other; to listen, observe and understand-not necessarily to agree, but to be able to comprehend.

If this is true for someone who, as a diplomat, is posted in a foreign land, it is also the obligation of any country that desires to play a part in today's world. Taking action without contemplating its consequences or expecting others to fully understand a given deed without considering the existence of different viewpoints may be counterproductive at best or reckless at most. None of these serves foreign policy correctly.

Narrowing the gap between reality and perception, making sure the latter is as close as possible to the former, is, therefore, essential for all international actors, so that they are fully understood, correctly analysed and properly assessed. To achieve this, a joint effort is required. The observer needs to fight off its potential pre-conceived ideas or bias. The observed party needs to be aware that those might still exist.

World history is full of examples that illustrate the complexity of this exercise. Moreover, today's international stage is a powerful reminder of how difficult this task is.

\section{The Centrality of Values and Principles}

There is, however, a common ground that allows all to share a joint perspective and where the risk of misperception can be greatly reduced: the values and principles we share.

Since at least 1945, the notion that there are universal principles common to all of humanity has been deeply integrated into the international system. These do not imply a notion of superiority, but rather of union. They do not aim to impose, but rather to share. And, they are not a power tool, but rather a tool for empowerment.

The fact that these values and principles are widely shared should, therefore, be seen as a conquest and a victory, as it represents a common ground on which we can build. A discourse based on these values does not need to be seen as a lecture, as different views on how to achieve some of them do not need to be taken as deviations from its importance. 
As the current international set of shared values and principles demonstrates, there is always room for debate and improvement. Some of those that are taken for granted today were the result of strong debates some decades ago.

With this evolution, there came great responsibility. What may be viewed by some as interference may be thought of by others as a direct consequence of transparency, information and joint accountability to values and principles enshrined in international documents signed by all. What others may think of as a tool to diminish certain feats and conquests should be taken up by others as an opportunity to showcase the implementation of a commitment to development in all of its dimensions.

\section{The Relevance of Rules and Norms}

All of this is made possible because ours is a rules-based international order. International law, the end of secret pacts or treaties, the ability to jointly define norms and patterns through dialogue, cooperation and an open exchange of views are some of the world's most important achievements.

Though sometimes discarded by some as a sign of weakness and viewed by others as a tool to be used only when that is deemed useful, the notion that the world has a set of rules and norms that is shared by all and that can be jointly shaped, defined and, therefore, understood is a development that cannot be underestimated.

The United Nations plays a central role in this common and shared architecture. An organization where all countries are equal, despite of their size, economic weight or geographic location; an organization where all issues_-big or small—are jointly discussed and analysed; an organization that shapes our daily lives.

Whether telecommunications, global health or trade, the United Nations has, through its various specialized agencies, created a more unified and connected world. Unity and connection equal stability, and stability means predictability, for states, but also for businesses and individual citizens.

All of this has made globalization possible. It enabled trade to flourish, barriers to be taken down and knowledge to be shared. It brought countries and peoples closer. Its benefits in terms of economic development, poverty alleviation or technological advancements are beyond anything the world that had ever seen before. And, all of this was made possible because there were common rules and a shared desire to develop others when and where needed. The World Trade Organization is a perfect example of this. Its creation represented a fundamental stepping stone for the current rules-based international order. And, the current debate on its reform signifies that there is joint understanding that this track record needs to be kept and updated to fit into today's world.

Temptations to deviate from this shared rule book or to drive some out of this joint undertaking are, therefore, detrimental to the whole world, for they stand in contrast with what enabled us to reach this far: a stage where trade is both free and fair; one where commitments are made and respected and where development needs 
are understood, but do not stand in the way of progress and respect for common values.

\section{The Example of Portugal}

Portugal is an example of the benefits brought about by this approach. A tripod based on an open and frank dialogue with all, a firm defence of shared values and a strong belief in the benefits of a rules-based international order, has been the hallmark of Portuguese foreign policy for decades. It is based on a widely shared political consensus at home and has served us well when navigating an increasingly complex international environment.

As a firmly pro-European country, Portugal has found in the European Union a perfect example of the benefits of this approach. Having joined in 1986, alongside Spain and thereby elevating the number of Member States of the then-European Community to twelve, Portugal is now a proud member of a family that brings together 27 countries; an organization where the pooling of sovereignty is not seen as a loss, but as a gain; where dialogue and compromise have replaced confrontation; where, despite the qualified majority rules in a vast array of areas, member states still try their best to reach a common position with which all can be comfortable. These achievements were not without its costs. They were made possible by a conscious decision to favour law instead of might and to listen before deciding rather than to impose.

This focus on dialogue and understanding is also what Portugal brings to the table when honouring its centuries-old relationship with many countries around the globe. Ours is a history of discovery and adventure; a journey made with people of different origins and backgrounds; a path paved with diversity and openness.

All of this makes Portugal acutely aware of the need to listen and to talk. It is what we do while at the helm of Presidency of the Council of the European Union, attempting to bring countries together and rally behind solutions and compromises that benefit the common good. It is how we act when interacting with countries and regions whose history, traditions and cultures are not the same as ours. It is the way we are.

This open identity is what makes us acutely aware of the need to engage with African countries and build a true partnership of equals, to maintain solid relations with Asian countries, whose importance for the world will only increase in the next few decades, and to defend the vitality and central importance for Europe of the transatlantic links - with both North and with Central and South America. 


\section{Global Challenges}

The current rules-based international order-where debate is possible and encouraged, norms are openly discussed and updated when necessary and international law is the glue that binds countries together-has been instrumental to the world's development and will be equally central when addressing the many challenges humanity is facing.

Climate change is the most evident and pressing of these. As there is only one planet and no "Plan B", there can be no other approach to deal with the effects of climate change other than a cooperative and multilateral one. With the Paris Agreement at the core and a common understanding of what needs to be done, namely achieving carbon neutrality, the world must invest in new and green technologies, phase out old and polluting ones, and thereby reap the social and economic benefits that will undoubtedly arise from a green transition.

In an age where countries are faced with the erosion of their coast lines, the desertification of their land or a loss of biodiversity that threatens agriculture and biological balance, climate change is a challenge that summons us all. It is, therefore, one where nationalism plays no part, as the gains of the one will be the gains of all, and the loss of the few will be felt throughout the globe.

The same applies to international cooperation on health issues, as the current pandemic so acutely demonstrates. In an age where no one will be safe until everyone is safe, international cooperation is fundamental to overcome a problem that has affected us all. While some may have more tools to deal with it, no instrument will be powerful enough to protect one given country or region from a problem that is global in nature which is why multilateralism, dialogue and cooperation are so important, particularly in defending a science-based approach or in the sharing of data and information in a transparent and verifiable way, as the development of vaccines has so clearly illustrated. Let us not forget that the majority of vaccine research and development was only made possible by multinational alliances between different countries and institutions, and even those which did not rely on such partnerships were only successful because science and the sharing of knowledge know there are no boundaries or limits.

\section{Conclusion}

Building a post-pandemic world will, therefore, require that all these lessons are correctly understood and incorporated into the way countries speak and act on the international stage. If cooperation and dialogue are essential in overcoming the challenges faced by all, shouldn't they also be the hallmark of the way we approach areas where understanding and common solutions are lacking?

Different countries with different cultures will probably always see and interpret certain facts in a different way. That does not mean that there is not a common ground 
uniting us all: the values we share, enshrined in international treaties, declarations and resolutions; the architecture jointly built by all, where the United Nations and international law play a central and fundamental role; and the common responsibility to talk and listen.

Certain countries, due to their size, population or economic weight, have a particular responsibility in driving this approach forwards, which is why the behaviour of some is more closely scrutinized than others. As with great power, there comes great responsibility, which should not come as a surprise, but rather as an incentive to do more and to do better for the benefit of all.

Diversity is one of the world's most enriching qualities, one that defines and challenges us, but also one which must not lead to forced isolation or forceful imposition. If we live in a global and interconnected world, the actions of one may and sometimes do impact others, which is why we must all-diplomats, politicians, civil society, academia-make an effort to think how one's actions may impact the view of others. This is why, the need to care and foster for our common values should not be seen as interference, but rather as a platform for dialogue and common improvement; why dialogue should never be cast aside; and why cooperation should always be the preferred option over confrontation. As foreign policy begins at home, the challenges of economic recovery and of the green and digital transitions should be seen as a way to take this common approach forwards.

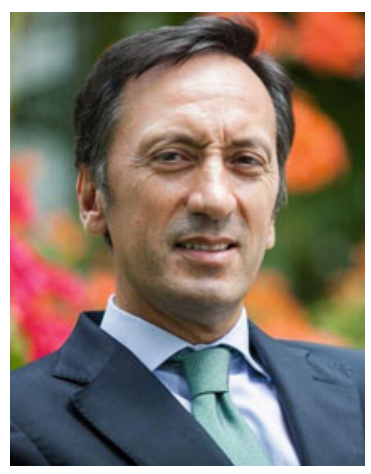

H.E. Mr. José Augusto Duarte is the ambassador of the Portuguese Republic to the People's Republic of China. He has been the ambassador of Portugal to China and Mongolia since 2017. Mr. Duarte was born in Lisbon in 1963 and graduated from the University of Lisbon, and his major is international relations. In 1990, Mr. Duarte joined the Ministry of Foreign Affairs and started his career working at the European Affairs Department and later in 1994 became the Adviser to the Minister of Foreign Affairs. He was the ambassador of Portugal to Mozambique and non-resident ambassador to the Seychelles, Swaziland, Mauritius and Tanzania. He also used to serve as the Chief Adviser to the President of the Portuguese Republic. 
Open Access This chapter is licensed under the terms of the Creative Commons AttributionNonCommercial-NoDerivatives 4.0 International License (http://creativecommons.org/licenses/bync-nd/4.0/), which permits any noncommercial use, sharing, distribution and reproduction in any medium or format, as long as you give appropriate credit to the original author(s) and the source, provide a link to the Creative Commons license and indicate if you modified the licensed material. You do not have permission under this license to share adapted material derived from this chapter or parts of it.

The images or other third party material in this chapter are included in the chapter's Creative Commons license, unless indicated otherwise in a credit line to the material. If material is not included in the chapter's Creative Commons license and your intended use is not permitted by statutory regulation or exceeds the permitted use, you will need to obtain permission directly from the copyright holder.

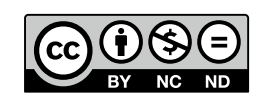

